\title{
O direito à alimentação nas escolas da rede pública de ensino do estado do Piauí
}

\section{frente à pandemia da Covid-19}

The right to food in schools of the public education network in the state of Piauí facing the Covid-19 pandemic

\section{EI derecho a la alimentación en las escuelas de la red de educación pública del estado de Piauí}

\author{
frente a la pandemia del Covid-19
}

Recebido: 11/10/2021 | Revisado: 18/10/2021 | Aceito: 22/10/2021 | Publicado: 24/10/2021

\author{
Rayssa Maria de Sousa Silva \\ ORCID: https://orcid.org/0000-0001-8926-398X \\ Secretaria de Estado da Educação do Piauí, Brasil \\ E-mail: rayssa_mss@hotmail.com \\ Daisy Jacqueline Sousa Silva \\ ORCID: https://orcid.org/0000-0002-3308-0700 \\ Universidade Federal do Piauí, Brasil \\ E-mail: d.jack204@hotmail.com \\ Ana Karine Carneiro de Albuquerque \\ ORCID: https://orcid.org/0000-0002-1393-1651 \\ Secretaria de Estado da Educação do Piauí, Brasil \\ E-mail: aninha_albuquerque0803@ hotmail.com \\ Lucélia Nárjera de Araújo \\ ORCID: https://orcid.org/0000-0001-5058-425X \\ Universidade do Vale do Rio dos Sinos, Brasil \\ E-mail: lu_narjera@yahoo.com.br
}

\section{Resumo}

O presente trabalho teve como objetivo geral analisar as legislações e estratégias que nortearam o Estado do Piauí na garantia do Direito à Alimentação aos alunos da Rede Pública estadual durante a crise da Pandemia pela Covid-19. Trata-se de uma análise documental dos principais atos normativos que tratam sobre o direito à alimentação no âmbito escolar. Para delimitação do período de análise, identificou-se as legislações, decretos e estratégias frente a pandemia no âmbito da alimentação escolar publicadas e implementadas de março a dezembro de 2020. Nesta perspectiva apresentase a evolução dos direitos humanos, do direito humano à alimentação até sua concepção como garantia no texto constitucional brasileiro e a importância do Programa Nacional de Alimentação Escolar (PNAE) na consolidação do Direito à Alimentação. Ressalta-se que o PNAE é o mais antigo e importante programa de alimentação de política pública de segurança alimentar e nutricional no Brasil. Por fim, realizou-se a análise das legislações e estratégias do Estado do Piauí para garantir aos alunos da rede pública estadual acesso à alimentação adequada durante o período de suspensão das aulas em decorrência da crise da Covid-19.

Palavras-chave: Direitos humanos; Direito à alimentação; Programa Nacional de Alimentação Escolar; Covid-19.

\begin{abstract}
The present work had as general objective to analyze the legislation and strategies that guided the State of Piauí in guarantee the Right to Food to the students of the State Public System during the Pandemic crisis by Covid-19. It is a documentary analysis of the main normative acts that deal with the right to food in the school environment. To delimit the analysis period, we identified the legislation, the decrees, and the strategies against the pandemic in the context of school feeding published that implemented from March to December 2020. In this perspective, the evolution of human rights is presented, from the human right to food to its conception as a guarantee in the Brazilian constitutional text and the importance of the National School Feeding Program (PNAE) in consolidating the Right to Food. It is noteworthy that the PNAE is the oldest and most important food program in Brazil's public food and nutrition security policy. Finally, an analysis of the legislation and strategies of the State of Piauí was carried out to guarantee public school students access to adequate food during the period of suspension of classes due to the Covid-19 crisis.
\end{abstract}

Keywords: Human rights; Right to food; National School Feeding Program; Covid-19.

\section{Resumen}

El presente trabajo tuvo como objetivo general analizar las legislaciones y estrategias que guiaron al Estado de Piauí en garantizar el Derecho a la Alimentación a los estudiantes del Sistema Público Estatal durante la crisis de la Pandemia por Covid-19. Se trata de un análisis documental de los principales actos normativos que abordan el derecho a la 
alimentación en el ámbito escolar. Para delimitar el período de análisis, se identificó la legislación, decretos y estrategias contra la pandemia en el contexto de la alimentación escolar publicados e implementados de marzo a diciembre de 2020. En esta perspectiva, se presenta la evolución de los derechos humanos, desde el derecho humano a la alimentación hasta su concepción como garantía en el texto constitucional brasileño y la importancia del Programa Nacional de Alimentación Escolar (PNAE) en la consolidación del Derecho a la Alimentación. Cabe destacar que el PNAE es el programa alimentario más antiguo e importante de la política pública de seguridad alimentaria y nutricional de Brasil. Finalmente, se realizó un análisis de la legislación y estrategias del Estado de Piauí para garantizar a los estudiantes de las escuelas públicas el acceso a una alimentación adecuada durante el período de suspensión de clases por la crisis del Covid-19.

Palabras clave: Derechos humanos; Derecho a la alimentación; Programa Nacional de Alimentación Escolar; Covid19.

\section{Introdução}

Em janeiro de 2020, a OMS já havia declarado que o surto do novo coronavírus constituía uma Emergência de Saúde Pública de Importância Internacional (ESPII) - o mais alto nível de alerta da Organização. Em 11 de março de 2020 , a Organização Mundial da Saúde - OMS caracterizou a Covid-19, doença causada pelo novo coronavírus, como pandemia (WHO, 2020).

Com a chegada da Covid-19 no Brasil, diversas medidas de controle e prevenção da doença foram tomadas pelas autoridades sanitárias. Essas medidas se diferenciaram de uma região para outra, entretanto a mais difundida foi a prática do distanciamento social (Bezerra et al, 2020).

O isolamento social, a depender do nível de gravidade da pandemia, tem sido a resposta mais eficaz, defendida pelas autoridades sanitárias de todo o mundo e adotada pela maioria dos governos mundiais na tentativa de reduzir exponencialmente o nível de letalidade (Bicalho \& Lima, 2020)

O direito à alimentação escolar é assegurado pelo artigo 208, inciso VII da Constituição Federal de 1988. Entretanto, Amorim et al (2020) aponta que por conta do isolamento social para o enfrentamento da pandemia da Covid-19, o Programa Nacional de Alimentação Escolar - PNAE se encontrava frente a um enorme desafio para continuar com o fornecimento da alimentação escolar.

No Brasil, para alguns alunos, principalmente os de condições socioeconômicas menos favorecidas, a alimentação escolar é primordial, pois muitas vezes ele é sua principal ou única refeição do dia (Mota et al, 2013). No Piauí, a situação de pobreza e extrema pobreza se evidencia principalmente nos municípios mais afastados dos polos econômicos do Estado. Segundo IBGE (2020) o Piauí encontra-se como quinto estado da federação na linha de extrema pobreza.

Tendo em vista esta realidade, o seguinte estudo se propôs a estudar a temática das ações relacionadas ao direito à alimentação nas escolas públicas da rede estadual do Estado do Piauí frente à pandemia da Covid-19.

A relevância no estudo do tema encontra-se na possibilidade de refletir sobre a realidade do impacto da pandemia na política pública de acesso a alimentação no ambiente escolar, sabendo-se que, a alimentação escolar é uma garantia constitucional e promove o fornecimento de refeições saudáveis aos alunos matriculados da rede pública. Assim, busca-se contribuir sobre o debate acerca da relevância em se garantir o fortalecimento do PNAE nas escolas, principalmente nos esforços das entidades governamentais, sociedade civil e comunidade escolar.

O presente trabalho tem como objetivo geral analisar as legislações e estratégias que nortearam o Estado do Piauí na garantia do Direito à Alimentação aos alunos da Rede Pública estadual durante a crise da Pandemia pela Covid-19.

\section{Metodologia}

O presente estudo de trata-se uma pesquisa qualitativa de análise documental dos principais atos normativos que tratam sobre o direito à alimentação no âmbito escolar, tendo como enfoque a leitura e análise de documentos oficiais que 
regulamentam a garantia do direito à alimentação bem como as implicações da pandemia pela Covid-19 no PNAE. Realizou-se o mapeamento teórico de trabalhos científicos sobre os direitos humanos, direito humano à alimentação adequada e alimentação escolar.

Utilizou-se como base de dados as informações e legislações disponíveis e divulgadas nos sites institucionais do Governo Federal, do Fundo Nacional de Desenvolvimento da Educação - FNDE, Governo Estadual do Piauí e da Secretaria de Estado da Educação do Piauí. Obteve-se diretamente da SEDUC-PI informações sobre a execução do PNAE no Estado do Piauí, através de requerimento de pedido de informação aberto no Sistema Eletrônico de Informações - SEI! Piauí, devidamente autorizado pelo setor competente para uso neste estudo.

Para delimitação do período de análise, identificou-se as legislações, decretos e estratégias frente a pandemia no âmbito da alimentação escolar publicadas e implementadas de março a dezembro de 2020.

\section{Resultados e Discussão}

\subsection{Os direitos humanos e o direito humano à alimentação adequada}

Em decorrência dos eventos devastadores que ocorreram durante o período da Segunda Guerra Mundial (1939-1945), os órgãos internacionais voltaram seu interesse à consolidação dos Direitos Humanos, com o objetivo de assegurar que crimes contra a humanidade, como o holocausto e os ataques nucleares às cidades de Hiroshima e Nagasaki, não voltassem a acontecer.

A primeira grande cristalização internacional do pensamento jurídico em matéria de direitos humanos foi a Declaração Universal dos Direitos Humanos, adotada em 1948, após os horrores da II Guerra Mundial. (FAO, 2014). Conforme Di Resende (2021) os Direitos Humanos consistem na positivação dos direitos fundamentais que são inerentes a natureza humana e à dignidade, devendo ser consagrados e garantidos por meio da intervenção do Estado, inclusive internacional. Dessa forma, a Soberania do Estado limita-se ao cumprimento prerrogativas humanitárias.

O Direito humano à alimentação adequada é emparado no artigo 25.1 da Declaração Universal dos Direitos Humanos que estabelece que toda pessoa tem direito a um nível de vida suficiente para lhe assegurar e à sua família a saúde e o bemestar, e para isso, aponta a alimentação como um dos componentes essenciais.

Em consequência de sua natureza jurídica, a Declaração Universal dos Direitos Humanos não vincula seus signatários. A partir desse pressuposto, houve a necessidade de outro instrumento jurídico internacional com poder vinculante que obrigasse os Estados membros a ratificar e aplicar o acordado.

Em dezembro de 1966 foi elaborado pela Assembleia Geral das Nações Unidas o Pacto Internacional sobre Direitos Econômicos, Sociais e Culturais - PIDESC em que os Estados Partes reconheceram o direito de todas as pessoas a um nível de vida suficiente para si e para as suas famílias

A partir daí, houve ampliação do direito à alimentação em decorrência da redação do artigo 11.2 do PIDESC o qual reconheceu o direito fundamental de todas as pessoas de estarem ao abrigo da fome, devendo os Estados adotarem individualmente e por meio da cooperação internacional as medidas necessárias, incluindo programas concretos.

Em 1999, a ONU, no sentido de interpretar o artigo 11.2 do PIDESC, elaborou o Comentário Geral número 12, esclarecendo que direito humano à alimentação adequada consiste na disponibilidade do alimento, em quantidade e qualidade suficiente para satisfazer as necessidades dietéticas das pessoas, livre de substâncias adversas e aceitável para uma dada cultura e acessibilidade ao alimento de forma sustentável e que não interfira com a fruição de outros direitos humanos.

Em seus estudos Oltramar et al (2020) afirma que os direitos humanos são inerentes a todas as pessoas e devem ser assegurados por políticas públicas que favoreçam o seu pleno exercício. A garantia dos direitos humanos, incluindo o direito humano à alimentação adequada (DHAA), foi conquistada por meio de muitas lutas e movimentos sociais ao longo do tempo. 


\subsection{O direito à alimentação na Constituição Brasileira de 1988}

A Constituição Federal de 1988 antecedeu ao Regime da Ditadura Militar (1964 - 1985), período marcado pelo autoritarismo e inúmeras violações aos Direitos Humanos. A concepção do texto constitucional é resultante do processo de redemocratização, e visava assegurar a proteção da pessoa humana e garantia de direitos fundamentais.

A promulgação da Constituição de 1988 agregou uma conquista política de valores sociais bastante relevantes, sobretudo, com relação aos direitos relativos às pessoas, levando-a, inclusive, a ser conhecida como Constituição Cidadã. (Ávila et al 2019). O direito à alimentação é produto das lutas sociais, da ação de minorias, que propiciaram que a fome fosse debatida e seu enfrentamento se tornasse uma obrigação social (Bicalho \& Lima, 2020)

Apesar dos avanços em questão de direitos humanos, a Constituição Federal de 1988, à época da sua concepção, não comtemplou direitos fundamentais como alimentação, transporte e moradia no seu artigo $6^{\circ}$, passando por modificações mediante a aprovação de Emendas Constitucionais no intuito de assegurar essas garantias no texto constitucional.

A inclusão do direito à alimentação foi resultado, principalmente, de amplo processo de mobilização social, sendo aprovada mediante Emenda Constitucional n ${ }^{\circ} 64$ de 2010, integralizando o artigo $6^{\circ}$ da Constituição Federal, o qual atualmente vigora a seguinte redação:

$C F, 88$. Art. $6^{\circ}$ São direitos sociais a educação, a saúde, a alimentação, o trabalho, a moradia, o transporte, o lazer, a segurança, a previdência social, a proteção à maternidade e à infância, a assistência aos desamparados, na forma desta Constituição.

Em seus estudos sobre a inclusão do direito à alimentação no rol do artigo $6^{\circ}$ da Constituição Federal, Oliveira \& Servegnini (2010) defendem o indiscutível alcance social, pois o direito à alimentação vem para complementar o direito à dignidade da pessoa humana, direito fundamental base da carta magna brasileira. Para as autoras, o direito à alimentação passa a ser intrinsecamente vinculados à igualdade e a dignidade da pessoa humana, que asseguram aos indivíduos condições materiais necessárias para a sobrevivência digna, consubstanciando pressupostos indispensáveis para o exercício da cidadania.

Além do direito à alimentação como direito social, a Constituição brasileira prevê a alimentação escolar como direito constitucional regulamentado pelo artigo 208, inciso VII, do texto constitucional que determina como dever do estado a garantia do atendimento ao educando por meio de programa suplementar de alimentação.

CF, 88. Art. 208. O dever do Estado com a educação será efetivado mediante a garantia de: VII - atendimento ao educando, em todas as etapas da educação básica, por meio de programas suplementares de material didáticoescolar, transporte, alimentação e assistência à saúde.

\subsection{O Programa Nacional de Alimentação Escolar (PNAE)}

\subsubsection{A evolução da alimentação escolar no Brasil}

A alimentação no âmbito escolar passou por inúmeros avanços até chegar ao formato conhecido atualmente. Foi a partir do Decreto n 3 37.106, de 31 de março de 1955 que se instituiu a companhia da Merenda Escolar cuja ação se estendia a todo território e poderia ser realizada diretamente através da criação de cantinas escolares ou mediante convênios a serem firmados com entidades públicas ou particulares.

No ano de 1956, em razão do Decreto $\mathrm{n}^{\circ} 39.007$ de 11 de abril, passou-se a denominar Campanha Nacional de Merenda Escolar acrescentando-se às suas finalidades a faculdade de estender seus programas de assistência e educação alimentar às instituições gratuitas de educação pré-primária, supletiva e de grau médio. Integrou-se ao II Programa Nacional de Alimentação e Nutrição (PRONAN) a partir de 1976. Posteriormente, em 1979, passou a ser intitulado Programa Nacional de Alimentação Escolar, denominação utilizada atualmente. 
Entretanto, é indiscutível que os principais avanços relacionados ao direito à alimentação escolar ocorreram após a promulgação da Constituição Federal de 1988 que tinha o propósito de assegurar o direito à alimentação escolar ao delegar ao Estado o dever de garantir o atendimento ao educando, no ensino fundamental através de programas suplementares de alimentação.

Desde sua concepção o PNAE possuía a gestão dos recursos de forma centralizada, isso significa que o governo federal era o responsável pelo planejamento e compra dos gêneros alimentícios, possuindo, ainda, a responsabilidade pela distribuição dos alimentos aos entes federativos.

Com a Lei no 8.913 de 12 de julho de 1994, iniciou-se o processo de descentralização da gestão do recurso do PNAE, a priori, com alunos da educação pré-escolar e ensino fundamental e, posteriormente, o dinheiro passou a ser repassado diretamente aos Estados, ao Distrito Federal e os Municípios proporcionalmente à matrícula.

Em 2009 foi sancionada a Lei no 11.947 , de 16 de junho que dispõe sobre o atendimento da alimentação escolar e do Programa Dinheiro Direto na Escola aos alunos da educação básica, nesta perspectiva houveram novos avanços para o PNAE dentre as principais, a garantia de fornecimento de alimentação escolar para toda a rede pública de educação básica e determinação da garantia de que, no mínimo, 30\% dos repasses do FNDE sejam investidos na aquisição de produtos da agricultura familiar, medida que buscava estimular o desenvolvimento econômico e sustentável das comunidades.

\subsubsection{O direito à alimentação e o PNAE}

A Constituição Federal de 1988, ao universalizar o direito à alimentação escolar e definir que este deve ser garantido pelos três níveis de governo, foi o impulso decisivo para a transformação do PNAE em política de Estado (Amorim et al 2020). Na perspectiva do direito à alimentação, o PNAE oferece aos estudantes acesso a ações de educação alimentar e nutricional e oferta de refeições com o objetivo de promover o crescimento e o desenvolvimento biopsicossocial, a aprendizagem, o rendimento escolar e a formação de hábitos alimentares saudáveis.

Ao estudar o registro histórico do Programa Nacional de Alimentação Escolar - PNAE, Peixinho (2011) afirmou que:

O PNAE, popularmente conhecido como merenda escolar, é um dos maiores Programas de alimentação escolar do mundo com o princípio da universalização e gratuidade na oferta de refeições e, ainda, com participação social, incluindo entre suas principais diretrizes o Direito Humano a Alimentação Adequada, com ênfase na alimentação saudável, desenvolvimento local, bem como a clarificação das ações de educação alimentar e nutricional e a oferta dos alimentos nas escolas.

Buscando fortalecer a PNAE como direito à alimentação e garantia fundamental, a Resolução/CD/FNDE n 38, de 16 de julho 2009 que dispõe sobre o atendimento da alimentação escolar aos alunos da educação básica no PNAE, considera que a alimentação adequada é um direito fundamental do ser humano, reconhecido internacionalmente pela Declaração Universal dos Direitos Humanos (art. 25) e pelo Pacto Internacional de Direitos Econômicos, Sociais e Culturais - PIDESC (art. 11).

Analisando as Capacidades Estatais no Programa Nacional de Alimentação Escolar, Ferreira et al (2021) observa que a consolidação do PNAE se posiciona em um contexto de expansão e fortalecimento dos sistemas nacionais de políticas públicas, marcado pela reconfiguração das relações entre Estado e sociedade.

\subsubsection{O PNAE no âmbito da Secretaria de Estado da Educação do Piauí}

O Piauí possui 224 municípios que são distribuídos geograficamente em 21 Gerências Regionais de Educação, dentre as quais quatro destas atuam no suporte à gestão das escolas situadas em Teresina, em razão da concentração maior de alunos na capital. No ano letivo de 2020, a rede estadual atendeu o total de 207.948 alunos distribuídos nas 650 unidades escolares do Estado. 
A rede estadual de educação atende alunos nas modalidades fundamental, médio e EJA (Educação de Jovens e Adultos) em tempo parcial, integral, pedagogia da alternância, cursos profissionalizantes, além dos alunos de AEE (atendimento educacional especializado), quilombolas, indígenas e os cursinhos preparatórios ENEM.

A seguir apresenta-se a Figura 1 que demonstra o total de recursos financeiros transferidos pelo FNDE à Secretaria de Educação do Piauí nos últimos 5 (cinco anos) para custeio, em caráter suplementar, da alimentação escolar. Observa-se que em 2017 houve incremento do valor repassado pelo governo federal, em razão da Resolução CD/FNDE/MEC N 1 , de 8 de fevereiro que a alterou os valores de per capita de todas as modalidades de ensino para oferta de alimentação, e passando a incluir estudantes contemplados no Programa de Fomento às Escolas de Ensino Médio em Tempo Integral.

Figura 1 - Recursos transferidos pelo FNDE à Secretaria de Estado da Educação do Piauí no período de 2016 a 2020 para execução do PNAE.

\section{Total de Recursos Transferidos pelo FNDE à SEDUC - PI}

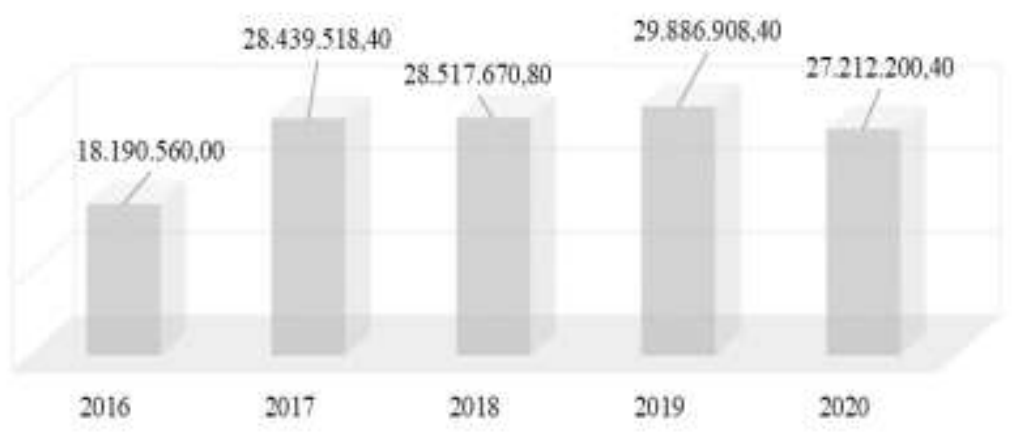

Total de Recursos Transferidos pelo FNDE à SEDUC - PI

Fonte: Site do FNDE, liberação de recurso ${ }^{1}$.

A Secretaria de Estado da Educação do Piauí - SEDUC - PI é o órgão executivo responsável por formular a política de educação do Piauí e administrar o sistema de ensino estadual. No contexto do PNAE, a SEDUC é a Entidade Executora do programa, ou seja, é responsável pelas ações de execução do PNAE e pela utilização dos recursos transferidos pelo Fundo Nacional de Desenvolvimento Escolar - FNDE.

A SEDUC - PI possui a forma de gestão descentralizada, assim, os recursos recebidos pelo FNDE são transferidos diretamente às Unidades Executoras (Unidades Escolares) em valores diferenciados conforme as modalidades de ensino oferecidas e proporcionais à quantidade de alunos matriculados.

O Governo Estadual do Piauí realiza complementação do valor repassado pelo FNDE aos alunos atendidos por meio de recursos próprios. Abaixo apresenta-se a Figura 2 que demostra o total recurso gasto na alimentação dos alunos da rede fonte do Tesouro Estadual no período de 2016 a 2020, nota-se que os valores repassados pelo Governo Estadual são variáveis e não havendo constância de valores a serem transferidos, além disso, em 2020 ocorreu a menor transferência nos últimos 5 anos.

\footnotetext{
${ }^{1}$ FNDE. Fundo Nacional de Desenvolvimento da Educação. FNDE - Programas - PNAE - Liberação de Recursos. Brasília - DF. https://www.fnde.gov.br/sigefweb/index.php/liberacoes.
} 
Figura 2 - Recursos do tesouro estadual transferidos pelo Estado do Piauí às escolas estaduais no período de 2016 a 2020 para execução do PNAE.

\section{Recurso tranferidos às escolas com fonte de recurso do tesouro estadual}

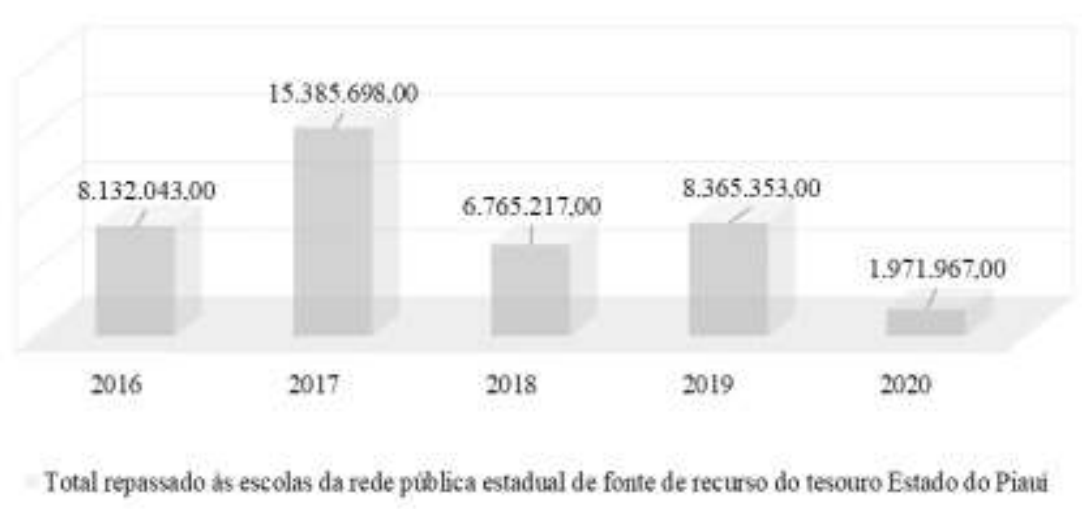

Fonte: Informações obtidas diretamente da SEDUC-PI.

Em seus estudos Amorim et al (2020) relata que a Lei do PNAE prevê que esse valor seja suplementado pelas esferas estaduais e municipais, entretanto, as desigualdades econômicas, sociais e regionais do país tornam a execução da política desigual, ainda que universal. Dessa forma, as Entidades Executoras detentores de menos recursos tendem a aplicar menores valores na suplementação, podendo inviabilizar o fornecimento de uma alimentação como prevê a lei.

\subsection{As legislações e estratégias para garantir o acesso à alimentação escolar durante a pandemia da Covid-19}

\subsubsection{A pandemia e a suspensão das aulas presenciais no estado do Piauí}

Como estratégia de enfrentamento a Covid-19 no Estado do Piauí, o primeiro texto legal deu-se através do Decreto Estadual 18.884, de 16 de março de 2020, que determinou medidas de emergência de saúde pública de importância internacional, o qual também regulamentou, em seu artigo 10, a imediata suspensão das aulas da rede pública estadual, a priori, durante um período de 15 dias.

No decreto supracitado também ficou regulamentado que os dados da situação epidemiológica da Covid-19 no Piauí seriam monitorados e avaliados pelos membros do Comitê de Operações Emergenciais (COE), que eram responsáveis por definir a necessidade de adoção de medidas de controle da disseminação do SARS-CoV-2.

Com a edição do Decreto Estadual de nº 18.895 de 19 de março de 2020, declarou-se estado de calamidade pública em razão da grave crise de saúde pública decorrente da pandemia da Covid 19, e suas repercussões nas finanças públicas.

À medida que os dados epidemiológicos eram analisados pelos membros do COE, outros decretos estaduais versando sobre medidas de controle da propagação da Covid-19 foram editados, bem como a prorrogação do período de suspensão das aulas em todo o Estado do Piauí.

A partir do dia 22 de setembro de 2020, em razão do Decreto Estadual n ${ }^{\circ}$ 19.219, de 21 de setembro de 2020, ficou autorizado o retorno das atividades do setor da educação, dentre estes, as atividades educacionais presenciais relativas ao $3^{\circ}$ (terceiro) ano do Ensino Médio e a turmas preparatórias para o exame nacional do ensino médio (Pré-ENEM) que atenderam às condições do Protocolo Geral e do Protocolo Específico.

\subsubsection{O PNAE frente a pandemia do Covid-19}

O PNAE é o mais antigo e importante programa de alimentação de política pública de segurança alimentar e 
nutricional no Brasil. Em 2020, em razão da pandemia de Covid-19 e consequente suspensão das aulas, o programa suspendeu a oferta de refeição para os alunos matriculados após décadas de atuação continuada.

Considerando o momento atual, a continuidade do ensino de maneira remota, somado ao esperado aumento da insegurança alimentar e nutricional decorrente da redução de renda das famílias, o PNAE se faz mais do que essencial e estratégico (Sperandio \& Morais, 2020). Na tentativa de garantir o direito à alimentação, o Piauí buscou estratégias que visassem assegurar a oferta dos recursos destinados à alimentação aos educandos, os quais serão expostos a seguir.

Em 02 de abril de 2020, o Governo do Estado do Piauí editou a Medida Provisória no 01 que autorizou, em caráter excepcional, a distribuição imediata aos pais ou responsáveis dos estudantes matriculados, de gêneros alimentícios em estoque ou de recursos financeiros à conta do PNAE, durante o período de suspensão das aulas nas escolas públicas de educação básica em razão de situação de emergência ou calamidade pública.

Para editar a medida provisória o Governo do Estado do Piauí, se fundamentou no art. $75, \S 4^{\circ}$, da Constituição Estadual, cuja redação regulamenta que em caso de calamidade pública, o Governador poderá adotar medidas provisórias com força de lei, devendo submetê-las, imediatamente, à Assembleia Legislativa. Posteriormente a medida provisória resultou na Lei Estadual n ${ }^{\circ} 7.374$, de 11 de maio de 2020.

Amorim et al (2020) relata que apesar de ser uma medida previsível, visto que outros países já enfrentavam, situações parecidas, não havia, por parte do FNDE, uma orientação sobre como as EEx deveriam proceder no fornecimento da alimentação escolar. Dada a urgência da situação, os gestores adotaram medidas distintas para continuar fornecendo alimentos aos escolares e, sem respaldo legal, se viram impossibilitados de utilizar os recursos do PNAE para essas ações.

Já o amparo legal do Governo Federal ocorreu em 7 de abril de 2020, por meio da Lei $\mathrm{n}^{\circ} 13.987$ que alterou a Lei ${ }^{\circ}$ 11.947, de 16 de junho de 2009, incluindo o art. 21-A, dado pela seguinte redação:

Art. 21-A. Durante o período de suspensão das aulas nas escolas públicas de educação básica em razão de situação de emergência ou calamidade pública, fica autorizada, em todo o território nacional, em caráter excepcional, a distribuição imediata aos pais ou responsáveis dos estudantes nelas matriculados, com acompanhamento pelo CAE, dos gêneros alimentícios adquiridos com recursos financeiros recebidos, nos termos desta Lei, à conta do PNAE.

Com isso, o FNDE editou a Resolução no 2, de 9 de abril de 2020 que regulamentou sobre a execução do Programa Nacional de Alimentação Escolar - PNAE durante o período de estado de calamidade pública, o qual autorizou a distribuição de gêneros alimentícios adquiridos no âmbito do PNAE às famílias dos estudantes, a critério do poder público local.

No dia 8 de maio de 2020 foi publicada a Resolução CD/FNDE $n^{\circ}$ 6, que estabelece novas normativas em relação à aplicação do PNAE, que deverão ser consideradas a partir da decretação do final do período de emergência e urgência em saúde pública diante da pandemia mundial do Covid-19.

A continuidade do PNAE, a despeito da suspensão das aulas, pauta-se na função estratégica do programa em relação à garantia do DHAA dos escolares, especialmente em uma situação em que são esperados efeitos deletérios na Segurança Alimentar e Nutricional de indivíduos e grupos populacionais (Pereira et al, 2020).

\subsubsection{O fornecimento de alimentação escolar aos alunos da rede estadual}

Para Amorim et al, 2020 a suspensão das aulas nas escolas públicas significou a interrupção ou a precarização do acesso à alimentação, o que não apenas impacta no orçamento das famílias, mas também prejudica quantitativa e qualitativamente a alimentação dos alunos.

Em virtude da suspensão das aulas nas escolas da rede estadual do Piauí, como forma de conter a propagação do novo 
coronavírus, a primeira medida do Governo do Estado do Piauí no sentido de garantir acesso à alimentação aos alunos matriculados na rede estadual de ensino foi a criação, em caráter de emergência, do Programa Merenda em Casa.

O Programa identificou os estudantes em situação de vulnerabilidade social inseridos no programa Bolsa Família cadastrados no CAD ÚNICO por intermédio de cruzamento de dados entre as bases da Secretaria de Estado da Educação e da Secretaria de Estado de Desenvolvimento Social ${ }^{2}$. Segundo a SEDUC-PI ocorreu o atendimento de 80.649 estudantes com transferência de recursos no valor per capita de $\mathrm{R} \$ 60,00$ (sessenta reais), custeado por recursos próprios.

Outro desafio ocorreu em virtude da presença de estoque de gêneros alimentícios nas escolas, que deveriam ser utilizados na oferta de alimentação no ambiente escolar. A medida tomada pela SEDUC-PI foi autorização da doação dos alimentos a alunos beneficiários do Programa Bolsa Família e de maior vulnerabilidade.

Após o respaldo legal do FNDE, a Secretaria de Estado da Educação do Piauí realizou a distribuição de gêneros alimentícios aos alunos na forma de kits de alimentos, adquiridos com recursos provenientes do PNAE. Cada kit alimentar tinha o valor per capita de $R \$ 25,00$ (vinte e cinco reais) para a compra de alimentos que deveriam ser elaborados e planejados pelo nutricionista responsável.

O kit de alimentos era constituído de gêneros alimentícios básicos e gêneros provenientes da Agricultura Familiar. Além de respeitar as diretrizes de oferta de alimentos do PNAE, compreendendo o uso de alimentos variados, seguros, que respeitem a cultura, as tradições e os hábitos alimentares saudáveis, a distribuição deveria seguir os protocolos sanitários pautados pela Secretaria visando minimizar o manuseio do alimento para evitar uma possível via de contaminação da Covid19.

Conforme Pereira et al (2020) para compor os kits de alimentos, em geral, é necessária uma quantidade maior de gêneros do que o empregado na produção de refeições que ocorre nas dependências das escolas, já que são necessários ajustes para adequar quantidades de alimentos de difícil fracionamento e até mesmo em função das embalagens disponíveis.

Souza et al (2021) ao analisar a (in)segurança alimentar no Brasil no pré e pós pandemia apontou que municípios que possuíam redes bem estruturadas de Segurança Alimentar e Nutricional se destacaram na proposição de ações em tempo oportuno para manter a alimentação dos alunos das escolas públicas e ainda que a entrega de kits com alimentos in natura para as famílias é uma estratégia que assegura qualidade nutricional da alimentação.

No que diz respeito ao retorno das aulas presencias foi recomendado pela SEDUC aos gestores das Unidades Escolares e às nutricionistas, responsáveis pelo planejamento e elaboração dos cardápios, o preparo de refeições práticas que reduzissem a manipulação do alimento e o risco de contaminação e, quando possível, adquirir preparações prontas, observando sempre as condições higiênicas sanitárias e a legislação vigente.

\section{Considerações Finais}

Tendo em vista a singularidade do momento vivenciado em decorrência da crise sanitária de nível pandêmico pela Covid-19, os entes federativos em conjunto com as autoridades sanitárias tiveram que tomar medidas que possibilitasse o controle da propagação da doença. Por outro lado, ainda que houvesse a adoção de medidas de isolamento, com a consequente suspensão das aulas, é dever do Estado garantir o direito à alimentação saudável dos alunos matriculados na rede pública de ensino.

Neste sentido, cabe ressaltar que a inércia do governo federal diante do avanço da infecção pelo novo coronavírus no país resultou em condutas diversas pelo poder público para o enfrentamento da doença que culminaram em diferentes estratégias dos entes federativos estaduais e municipais.

\footnotetext{
${ }^{2}$ Governo do Estado do Piauí. 2020. Governo do Piauí lança programa Merenda em Casa. https://www.pi.gov.br/noticias/governo-do-piauilanca-programa-merenda-em-casa- $2 /$.
} 
Analisando o Estado do Piauí, percebe-se que, concomitante ao decreto que reconhece o estado de calamidade pública, havia preocupação dos setores governamentais em propiciar o acesso à alimentação escolar aos alunos matriculados na rede, ainda que devido aos tramites burocráticos e legais houvesse certa letargia na efetividade da implementação dos recursos do PNAE.

Por fim, a garantia dos direitos constitucionais de acesso à alimentação escolar é uma temática importante e tem como consequência assegurar a Segurança Alimentar e Nutricional dos educandos. O cenário atual em decorrência da pandemia resultou em crise no campo econômico nos diversos setores produtivos gerando inflação, desemprego e instabilidade, refletindo na saúde física e mental dos indivíduos, além de agravar a situação de insegurança alimentar da população. Portanto, amplia-se para que outros estudos possam analisar a implicações da pandemia da Covid-19 na efetividade da garantia do direito à alimentação para a população, bem como avaliar as estratégias empregadas pelos entes federativos, quer seja União, Estados, Municípios e DF para promover acesso a itens alimentícios básicos à população mais vulnerável.

\section{Referências}

Amorim, A. L. B., Ribeiro Junior, J. R. S., \& Bandoni, D. H. (2020). Programa Nacional de Alimentação Escolar: estratégias para enfrentar a insegurança alimentar durante e após a COVID-19. Rev. Adm. Pública. 54 (4), 1134-1145.

Avila, J. L., Prado, N. T. H., \& Dias, E. F. (2019). Direitos Humanos na Constituição Federal Brasileira. Revista Jurídica Direito, Sociedade e Justiça, 8, 00.

Bezerra, A. C. V., Silva, C. E. M., Soares, F. R. G., \& Silva, J. A. (2020). Fatores associados ao comportamento da população durante o isolamento social na pandemia de COVID-19. Ciênc. saúde coletiva. 25(1), 2411-2421.

Bicalho, D. A., \& Lima, T. M., (2020). O Programa Nacional de Alimentação Escolar como garantia do direito à alimentação no período da pandemia da COVID-19. DEMETRA: Alimentação, Nutrição \& Saúde. 15, e52076. https://doi.org/10.12957/demetra.2020.52076.

Brasil. (1955). Decreto no 37.106, de 31 de março de 1955. Institui a companhia da Merenda Escolar. Diário Oficial da União. Seção 1. p.0.

Brasil. (1956). Decreto n ${ }^{\circ} 39.007$, de 11 de abril de 1956. Dá nova redação ao arts. $1^{\circ}, 2^{\circ}$ e $4^{\circ}$ do Decreto ${ }^{\circ} 37.106$ de 31 de março de 1955 . Diário Oficial da União. Seção 1. p. 7178.

Brasil. (1988). Constituição da República Federativa do Brasil. Senado Federal.

Brasil. (1994). Lei no 8.913, de 12 de julho de 1994. Dispõe sobre a municipalização da merenda escolar. Diário Oficial da União. Seção 1. p. 13469.

Brasil. (2009). Lei no 11.947 de 16 de julho de 2009. Dispõe sobre o atendimento da alimentação escolar e do Programa Dinheiro Direto na Escola aos alunos da educação básica. Diário Oficial da União. Seção 1. p.2.

Brasil. (2020). Lei no 13.987 de 07 de abril de 2020. Altera a Lei no 11.947 , de 16 de junho de 2009, para autorizar, em caráter excepcional, durante o período de suspensão das aulas em razão de situação de emergência ou calamidade pública, a distribuição de gêneros alimentícios adquiridos com recursos do Programa Nacional de Alimentação Escolar (PNAE) aos pais ou responsáveis dos estudantes das escolas públicas de educação básica. Diário Oficial da União. Edição Extra.

Brasil. (2009). Ministério da Educação. Fundo Nacional de Desenvolvimento da Educação - FNDE. Resolução/CD/FNDE no 38 de 16 de julho de 2009. Dispõe sobre o atendimento da alimentação escolar aos alunos da educação básica no Programa Nacional de Alimentação Escolar - PNAE. Diário Oficial da União. Seção 1. p. 10.

Brasil. (2017). Ministério da Educação. Fundo Nacional de Desenvolvimento da Educação - FNDE. Resolução/CD/FNDE nº 01 de 08 de fevereiro de 2017. Altera o valor per capita para oferta da alimentação escolar do Programa de Alimentação Escolar - PNAE. Diário Oficial da União. Seção 1. p.19.

Brasil. (2020). Ministério da Educação. Fundo Nacional de Desenvolvimento da Educação - FNDE. Resolução/CD/FNDE nº 02 de 09 de abril de 2020. Dispõe sobre a execução do Programa Nacional de Alimentação Escolar - PNAE durante o período de estado de calamidade pública, reconhecido pelo Decreto Legislativo $\mathrm{n}^{\circ}$ 6, de 20 de março de 2020, e da emergência de saúde pública de importância internacional decorrente do novo coronavírus - Covid-19. Diário Oficial da União. Seção 1. p.27.

Brasil. (2020). Ministério da Educação. Fundo Nacional de Desenvolvimento da Educação - FNDE. Resolução/CD/FNDE nº 06 de 08 de maio de 2020. Dispõe sobre o atendimento da alimentação escolar aos alunos da educação básica no âmbito do Programa Nacional de Alimentação Escolar - PNAE. Diário Oficial da União. Seção 1. p.38.

DI Rezende, M (2021). A Aplicabilidade das Decisões da Corte Interamericana de Direitos Humanos no Brasil. Editora Dialética.

Ferreira, V. B.; Vicari. L. M.; Carneiro, R (2021). Capacidades estatais no Programa Nacional de Alimentação Escolar (PNAE) em Minas Gerais: uma análise comparada da implementação nas redes estadual e municipal. Revista NAU Social. [S.1.],12(22), 578 - 599. https://doi.org/10.9771/ns.v12i22.33947.

Fundo Nacional de Desenvolvimento da Educação - FNDE. (2020). FNDE - Programas - PNAE - Liberação de Recursos. https://www.fnde.gov.br/sigefweb/index.php/liberacoes. 
Governo do Estado do Piauí. (2020). Governo do Piauí lança programa Merenda em Casa. https://www.pi.gov.br/noticias/governo-do-piaui-lanca-programamerenda-em-casa-2/.

Instituto Brasileiro de Geografia e Estatística - IBGE. (2020). Síntese de Indicadores Sociais. Uma análise das condições de vida da população brasileira 2020.

Mota, C. H., Mastroeni, S. S. B. S., \& Mastroeni, M. F. (2013). Consumo da refeição escolar na rede pública municipal de ensino. Revista brasileira de estudos pedagógicos. $94(236), 168-184$.

Oliveira, M. B. E., \& Servegnini, A. P. (2010). A inclusão do direito à alimentação no rol do artigo $6^{\circ}$ da constituição federal e a questão da eficácia dos direitos sociais. Revista Faz Ciência, 12(16), 179-198.

Oltramari, K.., Santos, L., Dias Guedes, J. R., Silva, A. F., Damasceno, C. S. B., Rodrigues, L. M. L., \& Galvão, M. R. M. (2020). Estratégias de enfrentamento da pandemia covid-19 na alimentação escolar do município de Curitiba - PR. Revista Contexto \&Amp; Saúde, 20 (41),80-89.

Organização das Nações Unidas para a Alimentação e a Agricultura - FAO. (2014). O Direito à Alimentação no quadro internacional dos Direitos Humanos e nas Constituições. Cadernos de Trabalho Sobre o Direito à Alimentação.

Peixinho, A. M. L. (2011). Um resgate histórico do Programa Nacional de Alimentação Escolar - PNAE. 2011. 133f. Dissertação (Mestrado Profissional). Universidade Federal de São Paulo, SP, 2011.

Pereira, A. S., Campos, F. M., Santos, C. R. B., Lima, E. C. S., Mocellin, M. C., Serra, G. M. A., Ferreirinha, M. L. C., \& Azevedo, A. B. C. (2020). Desafios na execução do Programa Nacional De Alimentação Escolar durante a pandemia pela COVID - 19. Brazilian Journal of Development. 6 (8), 63268-63282. https://doi.org/10.34117/bjdv6n8-674.

Piauí, Estado do (1989). Constituição Estadual (1989). Constituição do Estado Do Piauí. Teresina, PI, Assembleia Legislativa do Piauí. Diário Oficial do Estado do Piauí.

Piauí, Estado do (2020). Decreto Estadual no 18.884, de 16 de março de 2020. Regulamenta a lei no 13.979 , de 06 de fevereiro de 2020 , para dispor no âmbito do Estado do Piauí, sobre as medidas de emergência de saúde pública de importância internacional e tendo em vista a classificação da situação mundial do novo coronavírus como pandemia, institui o Comitê de Gestão de Crise, e dá outras providências. Diário Oficial do Estado do Piauí. n.50. p.5.

Piauí, Estado do (2020). Decreto Estadual n 18.895, de 19 de março de 2020. Declara estado de calamidade pública, para os fins do art. 65 da Lei Complementar $n^{\circ} 101$, de 4 de maio de 2000, em razão da grave crise de saúde pública decorrente da pandemia da Covid 19 , e suas repercussões nas finanças públicas, e dá outras providências. Diário Oficial do Estado do Piauí. n.53. p.1.

Piauí, Estado do (2020). Decreto Estadual no 19.219, de 21 de setembro de 2020. Aprova o protocolo específico com medidas de prevenção e controle da disseminação do Sars-CoV-2 (Covid-19) para o setor relativo à Educação, e dá outras providências. Diário Oficial do Estado do Piauí. n.178. p.3.

Piauí, Estado do (2020). Lei Estadual n $n^{\circ} 7.374$, de 11 de maio de 2020. Autoriza, em caráter excepcional, a distribuição imediata aos pais ou responsáveis dos estudantes nelas matriculados, de gêneros alimentícios em estoque ou de recursos financeiros à conta do PNAE, durante o período de suspensão das aulas nas escolas públicas de educação básica em razão de situação de emergência ou calamidade pública. Diário Oficial do Estado do Piauí. n.84. p.1.

Piauí, Estado do (2020). Medida provisória nº 01, de 02 de abril de 2020. Autoriza, em caráter excepcional, a distribuição imediata aos pais ou responsáveis dos estudantes nelas matriculados, de gêneros alimentícios em estoque ou de recursos financeiros à conta do PNAE, durante o período de suspensão das aulas nas escolas públicas de educação básica em razão de situação de emergência ou calamidade pública, e dá outras providências. Diário Oficial do Estado do Piauí. n. 63 - EDIÇÃO SUPLEMENTAR. p.1.

Souza, B. F. N. J., Bernardes, M. S., Vieira, V. C. R., P. M. S. B., Marín-León, L., Camargo, D. F. M., \& Segall-Corrêa, A. M. (2021). (In)segurança alimentar no Brasil no pré e pós pandemia da COVID-19: reflexões e perspectivas. InterAmerican Journal of Medicine and Health,4.

Sperandio N., \& Morais, D. C. (2021) Alimentação escolar no contexto de pandemia: a ressignificação e o protagonismo do Programa Nacional de Alimentação Escolar. Segurança Alimentar e Nutricional. 28(00), e021006.

United Nations (1948). Declaração Universal dos Direitos Humanos. Assembleia Geral das Nações Unidas em Paris. https://www.ohchr.org/EN/UDHR/Pages/Language.aspx?LangID=por.

United Nations (1966). Pacto Internacional sobre os Direitos Econômicos, Sociais e Culturais. Assembleia Geral das Nações Unidas. Resolução n.2.200-A (XXI). https://www.oas.org/dil/port/1966\%20Pacto\%20Internacional\%20sobre\%20os\%20Direitos\%20Econ\%C3\%B3micos, \%20Sociais\%20e\%20Culturais. pdf.

United Nations (1999). Comentário Geral número 12. O direito humano à alimentação (art.11). Comitê de Direitos Econômicos, Sociais e Culturais do Alto Comissariado de Direitos Humanos/ONU - 1999. https://fianbrasil.org.br/wp-content/uploads/2016/09/Coment\%C3\%A1rio-Geral-12.pdf.

World Health Organization - Who (2020). OMS afirma que COVID-19 é agora caracterizada como pandemia. Comunicados de impressa. https://www.paho.org/pt/news/11-3-2020-who-characterizes-covid-19-pandemic. 